\title{
A ILUMINAÇÃO NATURAL COMO FATOR DE DESEMPENHO EM AMBIENTES INDUSTRIAIS
}

\author{
NATURAL LIGHTING AS A \\ FACTOR IN PERFORMANCE \\ INDUSTRIAL ENVIRONMENTS
}

\author{
Data de submissão: 14-12-2014 \\ Aceite: 01-08-2015 \\ Eliane Garlet ${ }^{1}$ \\ Lucas Almeida Dos Santos ${ }^{2}$ \\ Larissa Disconzi Perufo 3 \\ Leoni Pentiado Godoy 4 \\ Lucina Fighera Marzall ${ }^{5}$
}

\section{RESUMO}

A busca por novas alternativas que maximizem seu desempenho no mercado econômico têm levado muitas empresas a investirem altos valores em produtos tecnológicos que permitam reduzir custos, aumentar sua lucratividade e garantir o eficaz desempenho de seus colaboradores nos processos produtivos. Diante disso, o presente artigo, caracterizado como um estudo de caso de caráter exploratório tem como objetivo analisar a implementação de um sistema de iluminação natural, integrado ao sistema de iluminação artificial, nas instalações industriais de uma empresa de grande porte do setor metalomecânico. Como principais resultados, foi possível verificar as vantagens que uma iluminação adequada pode oferecer, melhorando a produtividade de seus colaboradores e reduzindo os custos operacionais da empresa ao usar de forma sustentável a iluminação natural atrelada à iluminação artificial e, reduzindo também, futuros problemas de saúde dos funcionários.

Palavras-chave: tecnologias, iluminação, benefícios, redução de custos, ambientes industriais.

1 Possui graduação em Engenharia de Produção pela Faculdade Horizontina - FAHOR e mestrado em Engenharia de Produção pela Universidade Federal de Santa Maria - UFSM. Atualmente é professora substituta do Departamento de Engenharia de Produção e Sistemas na Universidade Federal de Santa Maria - UFSM. Santa Maria. Rio Grande do Sul. Brasil. E-mail: eligarlet@gmail.com

2 Possui graduação em Ciências Contábeis pelo Centro Universitário Franciscano - UNIFRA, graduação em andamento em Administração pelo Centro Universitário Franciscano - UNIFRA, graduação em andamento em Programa Especial de Graduação de Formação de Professores Para A Educação P. Universidade Federal de Santa Maria - UFSM e mestrado em andamento em Engenharia de Produção pela Universidade Federal de Santa Maria - UFSM. Santa Maria. Rio Grande do Sul. Brasil. E-mail: luksanttos@gmail.com

3 Possui graduação em Administração pelo Centro Universitário Franciscano - UNIFRA, graduação em andamento em Programa Especial de Graduação de Formação de Professores Para A Educação P. pela Universidade Federal de Santa Maria - UFSM e mestrado em andamento em Engenharia de Produção pela Universidade Federal de Santa Maria - UFSM. Atualmente é docente substituto no Instituto Federal Farroupilha - Câmpus Júlio de Castilhos e como pesquisadora no Núcleo de Pesquisa em Engenharia de Produção (NUPEP/UFSM). Santa Maria. Rio Grande do Sul. Brasil. E-mail: larissaperufo@hotmail.com

4 Possui mestrado e doutorado em Engenharia de Produção pela Universidade Federal de Santa Maria - UFSM. Atualmente é professor associado na Universidade Federal de Santa Maria - UFSM. Santa Maria, Rio Grande do Sul, Brasil. E-mail: leoni_godoy@ yahoo.com.br.

5 Possui graduação em Administração pela Universidade Federal de Santa Maria - UFSM. Santa Maria. Rio Grande do Sul. Brasil. E-mail: lucimarzall@gmail.com 


\begin{abstract}
The search for new alternatives that maximize its performance in the economic market have led many companies to invest high values on technological products that enable them to reduce costs, increase profitability and make increasingly effective performance of its employees in production processes. This exploratory paper, which will use a literature based on relevant literature to structure the proposed theme, also characterized as a case study in a large company of the mechanic metal sector, aims to analyze the usage implement a system of natural lighting, integrated with artificial lighting system in their plants, specifically in Hall A. As main results, we could verify the advantages that can be provided with adequate lighting, improving the productivity of its employees, in addition to reducing costs while operating the company to sustainably use the artificial lighting linked to natural lighting, as well as reducing future health problems of employees.
\end{abstract}

Keywords: technologies, lighting, benefits, cost reduction, industrial environments.

\title{
1 INTRODUÇÃO
}

No mercado competitivo, as empresas procuram opções para permanecer ativas, razão pela qual muitas delas investem em novas tecnologias dentro de suas instalações industriais, garantindo qualidade aos produtos, reduzindo acidentes de trabalho e reduzindo custos. Ao longo da história, o homem sempre planejou e construiu seus ambientes de labor, moradia, produção, lazer ou repouso de modo a favorecer suas necessidades vivenciais e sociais, influenciando as pessoas e o seu comportamento dentro das organizações (ОКАMOTO, 2002).

Atualmente, a maioria da população passa em média 80 a $90 \%$ do seu tempo dentro de edifícios, sendo preciso estabelecer condições de trabalho adequadas. Reitera-se que o ambiente visual interior adequado, por exemplo, é aquele que assegura ao trabalhador o conforto visual e a execução de diferentes tarefas visuais, sem perda de bem-estar. Assim, as recomendações e normas de iluminação devem ser baseadas não apenas nas necessidades físicas dos trabalhadores, mas também nas suas necessidades biológicas (CASTANHEIRA, 2012).

No ambiente de trabalho, uma boa iluminação precisa seguir uma gama de regras para satisfazer as necessidades visuais dos trabalhadores, tendo em vista fatores como nível de iluminação, uniformidade e ofuscamento. São necessários, dessa forma, atingir diversos parâmetros para a manutenção da saúde dos trabalhadores e a elevação do seu nível de desempenho (KOVALECHEN, 2012).

Além disso, a iluminação altera o ambiente térmico, que pode ser definido como o conjunto das variáveis térmicas que influenciam o organismo do trabalhador, interferindo de forma direta ou indireta em sua saúde e em seu bem-estar do mesmo e na realização de suas tarefas (LOPES, 2007).

Diante do exposto, o presente artigo, caracterizado como um estudo de caso, objetiva analisar a implementação de um sistema de iluminação artificial, bem como o promover reaproveitamento da iluminação natural, em uma empresa de grande porte atuante no setor metalomecânico e localizada na região noroeste do Rio Grande do Sul. Esta pesquisa se justifica devido às organizações procurarem meios para reduzir gastos e melhorar o desempenho produtivo de seus colaboradores, uma vez que o uso de novos métodos, como a utilização de iluminação artificial, traz um maior conforto térmico e luminoso, gerando, dessa forma, maior produtividade e satisfação dos colaboradores no ambiente de trabalho. 


\section{REVISÃO DE LITERATURA}

\subsection{Sistemas de iluminação natural e artificial}

O projeto de iluminação natural deve ser planejado sob o aspecto da sustentabilidade e estudado na concepção do empreendimento, minimizando custos e gastos com recursos e criando ambientes mais humanos, sustentáveis e economicamente viáveis. Ressalta-se que a iluminação natural e a radiação solar constituem aspectos para o conforto ambiental no interior dos edifícios, pois o papel da iluminação natural consiste em proporcionar um ambiente visual adequado (OLIVEIRA et al., 2009).

Uma maneira para reduzir o consumo de energia elétrica é melhorar a eficiência de alguns produtos amplamente utilizados no dia a dia, como, por exemplo, as lâmpadas (VALENTIM et al., 2010). Nesse sentido, o uso de lâmpadas com tecnologia avançada, reatores, luminárias e tecnologias light pipe pode reduzir significativamente o consumo de energia e os gastos com manutenção associados à iluminação de instalações industriais.

Além de sua maior durabilidade, os novos sistemas de iluminação proporcionam redução de calor nas áreas internas, resultando em menor carga de refrigeração, melhoria da segurança pela eliminação de fiação elétrica, possibilidade de utilização de outras fontes de luz não convencionais mais eficientes, mais específicas e esteticamente agradáveis, além de instalações e custos de manutenção reduzidos (CNI, 2013).

\subsection{A iluminação em ambientes produtivos}

A iluminação em um ambiente produtivo deve ser distribuída uniformemente pelo local, evitando ofuscamentos, sombras, cantos escuros, reflexos fortes e contrastes excessivos. Deve, também, incidir sobre uma direção que não prejudique os movimentos nem a visão dos colaboradores, proporcionando a realização das atividades com total eficácia.

De acordo com Van Bommel (2011), os níveis de iluminação em interiores sem a contribuição de luz natural estão entre 100 e 500 lux apenas, sendo geralmente determinados pelas normas que regem o tema. Em muitos casos, a luz natural adentra o ambiente produtivo por pelo menos algumas horas durante o dia, aumentando os níveis de iluminação substancialmente. Nesse sentido, outra diferença entre a iluminação natural e a artificial é a dinâmica na intensidade luminosa e na temperatura de cor que a luz natural apresenta. De maneira geral, aceita-se que tais alterações da iluminação natural exerçam uma influência positiva no humor dos trabalhadores, influência que pode ser duplicada com a iluminação artificial dinâmica.

Na concepção de Filho e Regis (2004), a visão é responsável por 75\% da informação sensorial percebida do cérebro, portanto, quando a iluminação não é adequada para um determinado ambiente, esta pode causar danos graves aos trabalhadores, gerando, inclusive, acidentes. Segundo Manav (2007), a presença de condições de conforto visual e psicológico assegura o bem-estar e aumenta a motivação do indivíduo, o que conduz a um maior desempenho e incremento na produtividade. Dessa forma, a iluminação deve ser adequada conforme a tarefa a ser executada, ou seja, levando em conta a quantidade e qualidade apropriada a fim de proporcionar ao colaborador um melhor conforto visual (PAIS, 2008).

Uma iluminação adequada é, assim, imprescindível em um ambiente de trabalho, pois sua ausência pode comprometer a segurança do colaborador e acarretar tensões psíquicas e fisiológicas, resultando em problemas de concentração na execução do trabalho, nervosismo, do- 
res de cabeça, fadiga etc. (LAMBERTS et al., 1997). Tendo isso em vista, a Consolidação das Leis do Trabalho (CLT), no Capítulo V, que versa sobre a Segurança e Medicina do Trabalho, prevê que em todos os locais de trabalho deverá haver iluminação adequada, natural ou artificial, apropriada à natureza da atividade (SANTOS et al., 2005).

Nesse sentido, a iluminância média recomendada para um ambiente de trabalho depende de vários fatores, tais como: velocidade, precisão e tipo de atividade que é realizada no ambiente; idade do colaborador que desenvolve as atividades; e regulamentações específicas exigidas para tal ambiente (FILHO et al., 2010).

Outro item bastante relevante é quanto ao conforto térmico advindo de um ambiente bem-iluminado. A esse respeito, Ruas (1999) elucida que o conforto térmico deve ser entendido como o sentimento de bem-estar manifestado pelas pessoas, considerando fatores como temperatura do ambiente, umidade relativa, velocidade relativa do ar, tipo de atividade desenvolvida no ambiente e vestimentas e equipamentos individuais necessários.

Acredita-se que as pessoas podem se adaptar ao ambiente térmico e que as condições de conforto variam conforme o clima exterior ao local. Dessa forma, os padrões internacionais de conforto térmico baseiam-se principalmente nas análises teóricas de calor humano e de dados obtidos em ambiente climatizados (OROSA; OLIVEIRA, 2011).

Nesse sentido, as condições de trabalho devem ser adaptadas às características psicofisiológicas dos colaboradores, proporcionando o máximo de conforto, segurança e produtividade (KUHN; OLIVEIRA; TAKEDA, 2010). Caso contrário, existirão efeitos danosos, tanto físicos quanto psíquicos, ao trabalhador (Figura 1).

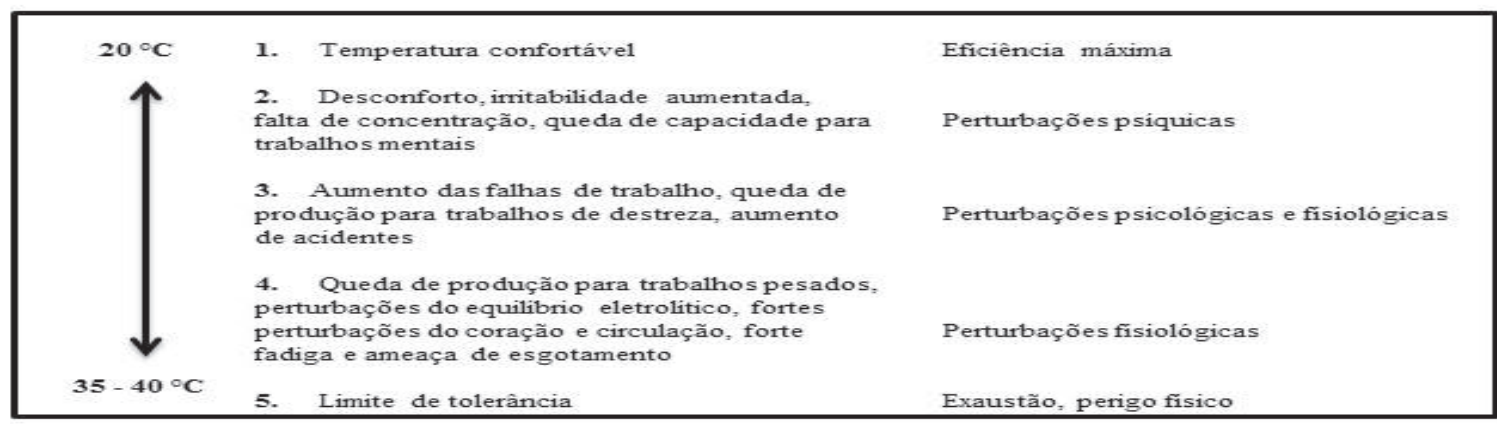

Figura 1: Efeitos dos desvios de temperatura no desempenho dos colaboradores.

Fonte: Kroemer e Grandjean (2005).

O trabalho sujeito tanto a altas quanto a baixas temperaturas impacta o rendimento dos colaboradores. Para uma condição de conforto térmico, é necessário que se tenha equilíbrio térmico, de modo que a quantidade de calor que o organismo seja igual à quantidade de calor liberado para o meio externo.

\section{METODOLOGIA}

A presente pesquisa foi realizada em uma empresa de grande porte da região noroeste do Rio Grande do Sul, atuante no setor metalomecânico, caracterizando-se como um estudo de caso (CAUCHICK, 2012). Esta pesquisa é de caráter exploratório, pois, primeiramente, foi necessário entender todo o projeto de instalação, realizando uma pesquisa bibliográfica e reuniões com as pessoas envolvidas no processo, a fim de analisar e descrever os benefícios advindos da implantação do sistema de iluminação natural. 
Por fim, o estudo realizado apresenta-se como qualitativo definido por Cauchick (2012) como toda pesquisa que se destina a obter informações sobre a perspectiva dos indivíduos, bem como a interpretar o ambiente em que a problemática acontece. Procedeu-se, ainda, à observação e descrição do ambiente pesquisado, para que todos os fatores envolvidos pudessem ser avaliados no presente estudo.

\section{RESULTADOS E DISCUSSÕES}

Conforme proposto, apresentar-se-á a análise da implantação de um sistema de iluminação artificial, além do reaproveitamento da iluminação natural, como forma de melhorar o desempenho dos colaboradores de uma organização, oferecendo melhores condições de trabalho em um ambiente apropriado para o desenvolvimento de suas atividades.

Nesse sentido, no que tange à questão do conforto térmico que a empresa procura para melhorar as condições de trabalho dos colaboradores, esta optou por utilizar um conceito diferenciado na engenharia civil do prédio, utilizando novos métodos de construção, a fim de permitir trocas naturais de ar no ambiente produtivo. Para isso, a empresa buscou novas alternativas de telhas, realizando primeiramente um comparativo entre os vários tipos que poderiam ser utilizadas para definir quais se adaptariam melhor à realidade esperada. Após as análises, foi escolhida a telha zenital prismática Medabil, pois esta apresentou melhores benefícios tendo em vista os interesses da empresa. Dessa forma, foram utilizadas telhas zenitais em $5 \%$ da área coberta, para que não houvesse impactos no conforto térmico interno do pavilhão, uma vez que esse tipo de telha permite a incidência da luz natural no ambiente produtivo.

Quanto ao aquecimento do ar, foi utilizado um sistema de ventilação/exaustão natural, o qual garante um total de seis trocas de ar por hora, naturalmente, em uma área de $7.500 \mathrm{~m}^{2}$, de modo que, a cada 10 minutos, todo o ar que está dentro do pavilhão se renova. Nessa renovação, o ar que está do lado de dentro do pavilhão, que se encontra mais aquecido, saturado e com impurezas, é substituído pelo ar de fora do pavilhão. Isso faz com que a sensação térmica no local permaneça agradável, fato que se comprova pelas medições de temperatura efetuadas em outros pavilhões da mesma empresa, tendo em vista que a temperatura do pavilhão em estudo é inferior às temperaturas nos outros pavilhões considerando-se um mesmo momento.

Assim, a empresa buscou uma solução para nivelar e controlar o uso da energia artificial dentro do ambiente produtivo. Para isso, foram analisadas três opções de iluminação artificial, conforme consta no Quadro 1, exposto a seguir.

\begin{tabular}{|c|c|}
\hline OPÇÕES DE ILUMINAÇÃo ARTIFICIAL ANALISADAS \\
\hline $\begin{array}{c}\text { Opção 1 - Alta Pressão Vapor metálico de iluminação } \\
\text { sem controle automatizado. }\end{array}$ \\
$\begin{array}{c}\text { Opção 2 - Alta Pressão Vapor metálico de iluminação } \\
\text { com controle automatizado. }\end{array}$ \\
$\begin{array}{c}\text { Opção 3 - Iluminação fluorescente com controle au- } \\
\text { tomatizado. }\end{array}$
\end{tabular}

Quadro 1: Opções de iluminação artificial.

Fonte: empresa pesquisada. 
Para que o projeto fosse implementado, fez-se necessário um investimento na nova tecnologia de iluminação artificial, sendo mensurados os custos e os benefícios para cada opção escolhida, conforme apresentado no Quadro 2.

\begin{tabular}{|c|c|c|c|}
\hline \multicolumn{4}{|c|}{ INVESTIMENTO INICIAL } \\
\hline \multirow[b]{2}{*}{ Descrição } & \multicolumn{3}{|c|}{ OPÇÕES } \\
\hline & 1 & 2 & 3 \\
\hline Instalação & $\mathrm{R} \$ 66.465,00$ & $\mathrm{R} \$ 66.465,00$ & $\mathrm{R} \$ 183.867,00$ \\
\hline Controle Automatizado & $\mathrm{R} \$$ - & $\mathrm{R} \$ 15.000,00$ & $R \$ 9.000,00$ \\
\hline Claraboias & $\mathrm{R} \$ 108.590,24$ & $\mathrm{R} \$ 108.590,24$ & $\mathrm{R} \$ 108.590,24$ \\
\hline Cabos Adicionados & $\mathrm{R} \$$ - & $\mathrm{R} \$ 5.000,00$ & $R \$ 5.000,00$ \\
\hline Trabalho Adicional & $\mathrm{R} \$$ - & $R \$ 5.000,00$ & $R \$ 5.000,00$ \\
\hline Total Investimento Inicial & $\mathrm{R} \$ 175.055,24$ & $\mathrm{R} \$ 200.055,24$ & $\mathrm{R} \$ 311.457,24$ \\
\hline \multicolumn{4}{|c|}{ CUSTO OPERACIONAL } \\
\hline \multirow[b]{2}{*}{ Descrição } & \multicolumn{3}{|c|}{ OPÇÕES } \\
\hline & 1 & 2 & 3 \\
\hline Substituição da lluminação R\$/mês & $\mathrm{R} \$ 345,45$ & $\mathrm{R} \$ 164,09$ & $\mathrm{R} \$ 816,51$ \\
\hline Consumo de Energia Elétrica $\mathrm{R} \$$ /mês & $\mathrm{R} \$ 5.998,18$ & $R \$ 2.368,68$ & $R \$ 2.009,04$ \\
\hline Descartes de Lâmpadas R\$̆/mês & $R \$ 2,05$ & $R \$ 0,97$ & $\mathrm{R} \$ 11,20$ \\
\hline Total Custo Operacional & $6.335,68$ & $2.803,64$ & $2.836,75$ \\
\hline Consumo de Energia Elétrica KWH/mês & $23.952,72$ & $10.554,72$ & $8.036,16$ \\
\hline Emissões m TCO 2/mês & 0,51 & 0,22 & 0,17 \\
\hline
\end{tabular}

Quadro 2: Investimento e custo operacional do projeto Fonte: empresa pesquisada.

Assim, como forma de verificar a viabilidade do projeto, foi realizada, levando em conta o investimento feito e os custos operacionais, uma análise econômica, comparando a opção 1 , que apresentou maior custo operacional, com as opções 2 e 3, que tiveram custos operacionais significantemente reduzidos, conforme destacado no Quadro 3.

\begin{tabular}{|c|c|c|c|c|}
\hline \multicolumn{4}{|c|}{ ANÁLISE ECONÔMICA } \\
\hline & \multirow{2}{*}{ Unidade } & $\mathbf{1}$ & $\mathbf{2}$ & $\mathbf{3}$ \\
\hline Descrição & OPÇ̃̃ES \\
\hline Economia (em relação à opção 1) & KWH/mês & & $13.398,00$ & $15.916,56$ \\
\hline Economia (em relação à opção 1) & $\mathbf{m}$ TCO 2/mês & & 0,29 & 0,34 \\
\hline Economia (em relação à opção 1) & $\mathbf{R}$ /mês & & $3.531,94$ & $3.498,93$ \\
\hline Payback simples (investimento adicional) & Mês & & 7,08 & 38,99 \\
\hline Payback simples (investimento total) & Ano & & 4,72 & 7,42 \\
\hline
\end{tabular}
Quadro 3 - Análise econômica do projeto.

Fonte: empresa pesquisada.

Analisando esses dados, a opção 2 é a que proporcionou maiores benefícios em termos de economia e vantagens perante as demais opções estudadas, composta por lâmpadas de alta pressão com vapor metálico e controle automatizado, conforme o Quadro 1, sendo então escoIhida pela empresa como o projeto mais viável para implantação.

Após escolha do projeto, foi utilizado, para fazer medições da iluminância dentro do ambiente, o controlador meteorológico, que consiste em um sistema que compara os dados determinados como padrão no equipamento e faz uma espécie de cálculo, para encontrar a iluminância que falta no ambiente e acionar, então, o circuito de energia elétrica da rede para que 
ocorra uma compensação de luz. Para que isso seja possível, um controlador lógico programável (CLP) de porte médio coordena essa dinâmica, sendo programado para garantir que, dentro do ambiente, haja uma quantidade específica de luz que atenda às condições perfeitas para o desenvolvimento das atividades.

O nível de iluminância adequada para o pavilhão analisado varia de 250 a 1000 lux. $\mathrm{Na}$ Figura 2, pode-se observar uma medição realizada no pavilhão industrial, indicando a iluminância média diária de cada mês projetada no período de um ano.

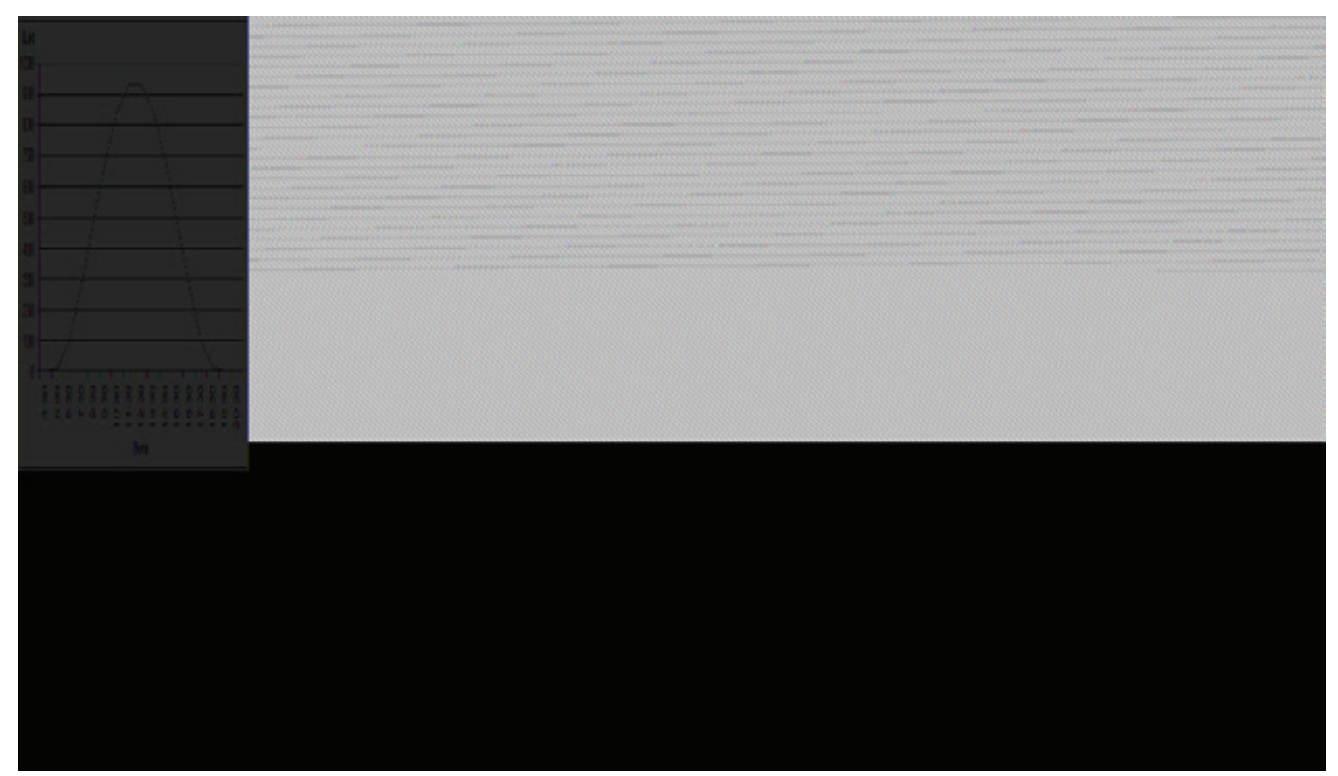

Figura 2 - Iluminância média diária de cada mês projetada.

Fonte: empresa pesquisada.

Analisando a Figura 2, observa-se que foi considerada a intensidade da iluminação natural que adentra no ambiente em diferentes períodos do dia. As medições foram realizadas de hora em hora, com base na variação dos meses, levando em conta que a contribuição solar muda de acordo com as condições climáticas e com a estação do ano. Para efeito de projeto, considerou-se uma curva média diária, conforme indica a Figura 3.



Figura 3: Média diária de iluminação natural.

Fonte: empresa pesquisada 
Para controlar a intensidade de luminosidade no Pavilhão A, faz-se uso do controlador meteorológico, que avalia a iluminância natural que está incidindo no ambiente e comanda o acionamento de lâmpadas por meio do CLP. O CLP é responsável por comandar, através do painel de distribuição, redes distintas de lâmpadas, conforme a necessidade de cada período. Dessa forma, quando necessário, esse controlador aciona apenas uma linha de lâmpada, fazendo com que a iluminação artificial passe a suprir $25 \%$ da necessidade de iluminação. Com a redução da iluminação natural, são acionadas mais lâmpadas, que representam mais $25 \%$ de luz artificial.

Ao final do dia, quando não houver mais luz natural, o CLP, por meio de um comando, irá acionar a última linha de lâmpadas elétricas, que representam $50 \%$ da iluminação do ambiente. A mesma dinâmica ocorre quando a luz natural começa a adentrar no ambiente, de modo que o CLP vai desligando as redes de lâmpadas elétricas gradativamente.

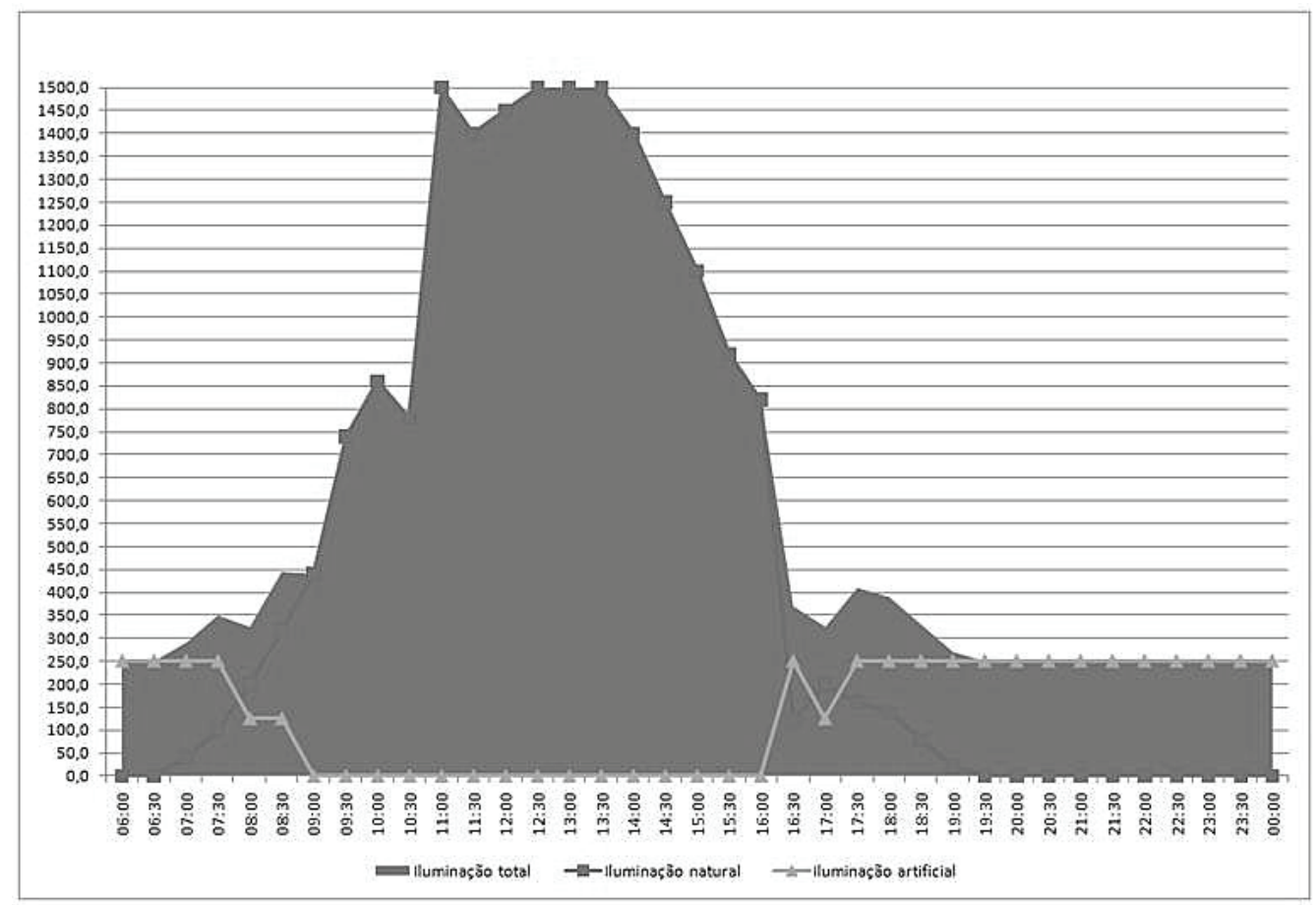

Figura 4: Variação da incidência da iluminação artificial e do uso de energia elétrica durante um dia. Fonte: empresa estudada.

Observando-se a Figura 4, é possível perceber a variação da incidência de luz natural e a complementação com a luz elétrica nos diferentes horários do dia. No local estudado, o período em que se tem o valor máximo de iluminação natural que satisfaz a condição de iluminância determinada adequada ocorre entre as 09 e as 16 horas, uma vez que nesse período a energia elétrica pode chegar ao nível zero de utilização, gerando uma redução de custos para a empresa, que passa a utilizar somente a luz natural em suas instalações.

Nessa área, tendo em vista a necessidade de uma iluminância maior que 400 lux, o sistema apresenta um comportamento em conformidade com a realidade confrontada. Sendo assim, o sistema responsável por deixar o ambiente em boas condições de iluminação é o controlador, que, mediante as informações recebidas dos sensores, atua de maneira eficaz para manter a iluminação de acordo com as necessidades de conforto visual dos colaboradores.

Com isso, a implantação de novas técnicas de iluminação que ocorreu no Pavilhão $A$ da empresa permitiu comparar o antes e o depois da implantação das telhas (Quadro 4). 


\begin{tabular}{|c|c|c|}
\hline Aspectos & $\begin{array}{c}\text { Antes da melhoria com CLP e } \\
\text { substituição do tipo das lâm- } \\
\text { padas }\end{array}$ & $\begin{array}{c}\text { Depois da melhoria com CLP e } \\
\text { substituição do tipo das lâm- } \\
\text { padas }\end{array}$ \\
\hline Quantidade de lâmpadas & 200 & 128 \\
\hline Potência elétrica & $436 \mathrm{~W}$ & $436 \mathrm{~W}$ \\
\hline Potência elétrica para iluminação & $87,2 \mathrm{KW}$ & $55,8 \mathrm{KW}$ \\
\hline Tipo de lâmpadas & Vapor de Mercúrio & Vapor Metálico \\
\hline Fluxo luminoso & $22000 \mathrm{~lm}$ & $35000 \mathrm{Im}$ \\
\hline
\end{tabular}

Quadro 4: Regime de trabalho intermitente.

Fonte: Guia Trabalhista - GT (2014).

Observa-se, no Quadro 4, que, após a implantação das telhas e a substituição das lâmpadas antigas que eram de vapor de mercúrio por lâmpadas de vapor metálico, consegue-se um maior resultado com menor quantidade de lâmpadas, pois, com a luz natural que adentra através das novas telhas, a iluminação diurna artificial é complementada, gerando maior luminosidade com menor consumo de energia, conforme Figura 5.

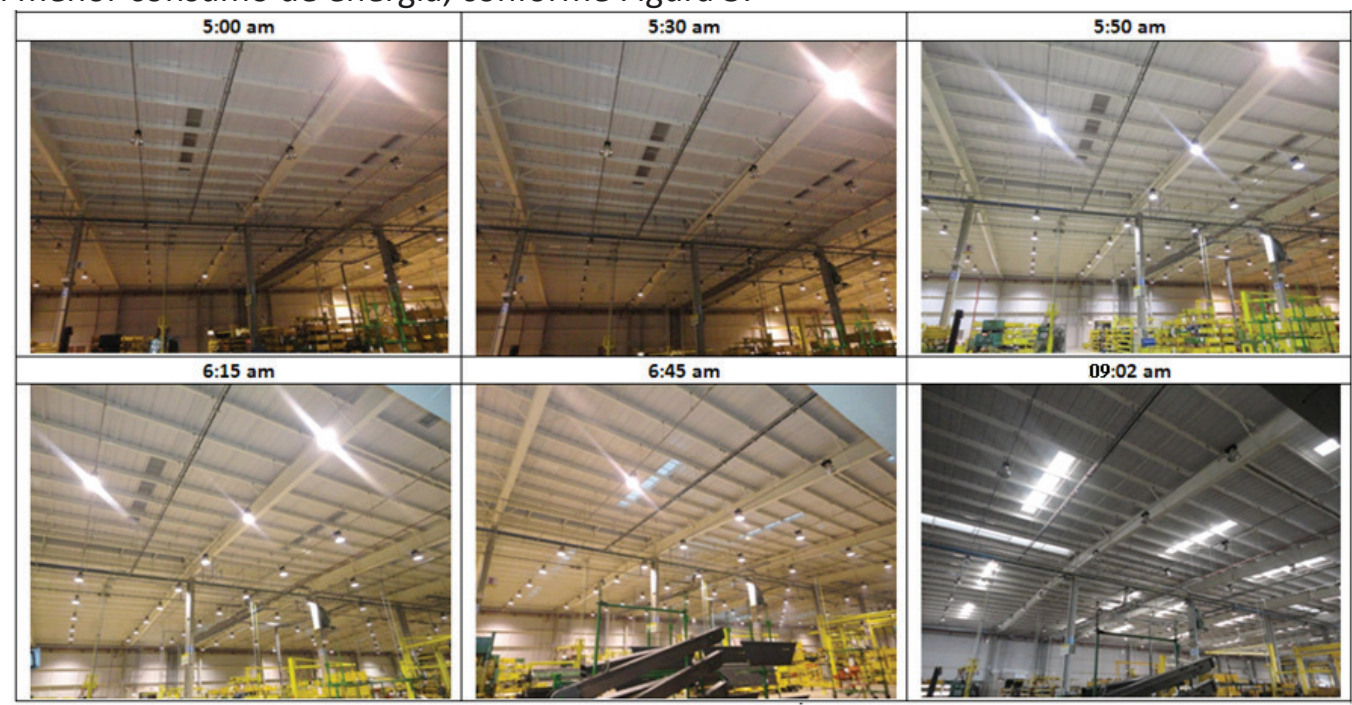

Figura 5: Nível de iluminação no ambiente e utilização da iluminação natural combinada com a artificial.

Fonte: empresa estudada.

Assim, percebe-se, ainda, conforme a Figura 5, que aproximadamente às 06h45min há incidência de iluminação natural no ambiente, momento em que as lâmpadas elétricas permanecem acesas para suprir a necessidade de iluminação. A partir das 09h02min, a iluminação artificial não é mais utilizada, havendo somente a incidência da iluminação natural.

\section{CONCLUSÕES}

No presente estudo, foi possível destacar a importância e os benefícios que a empresa estudada obteve por meio da implantação de um sistema de iluminação e conforto térmico, proveniente de tecnologia que entrelaça a iluminação artificial com a natural, mantendo o ambiente produtivo com boa luminosidade.

Percebeu-se que a empresa estudada realizou um alto investimento nesse quesito, proporcionando, assim, um ambiente agradável para que seus colaboradores pudessem desenvolver suas atividades. Assim, a empresa, além de obedecer às normas estipuladas pela Consolidação 
das Leis Trabalhistas (CLT), reduziu seus custos operacionais com energia elétrica, ocasionando uma redução que pode chegar a $60 \%$, e maximizou seus lucros, evitando, ainda, futuros problemas de saúde de seus funcionários.

Considerando esses dados, o retorno do investimento feito pela empresa é de aproximadamente um ano e meio. Isso evidencia a sustentabilidade do projeto, uma vez que a empresa buscou, por meio de um aproveitamento inteligente da iluminação natural, reduzir o consumo de energia elétrica da rede. Tais mudanças melhoram a qualidade do ambiente fabril e, consequentemente, a produtividade dos colaboradores, demonstrando, ainda, um olhar sustentável sobre o meio ambiente, o qual é fundamental para que as empresas permaneçam ativas no mercado.

Embora as conclusões obtidas neste estudo sejam baseadas em uma única empresa, as informações coletadas são pertinentes para que outras organizações implementem essas novas tecnologias em suas instalações industriais. Por fim, ressalta-se que este estudo evidenciou o sucesso em termos de qualidade de vida para os funcionários, além do aumento da produtividade e do crescimento da empresa fabril, gerados pela implementação da gestão integrada de iluminação.

\section{REFERENNCIAS}

CASTANHEIRA, L. M. Estudo da influencia da luz natural na qualidade da iluminação e na eficiência energética. Dissertação (Mestrado Engenharia Civil) - Faculdade de Ciências, Universidade Nova de Lisboa, Portugal, 2012.

CAUCHICK, M. P. A.; et al. Metodologia de pesquisa em engenharia de produção e gestão de operações. 2 ed. Elsevier: Rio de Janeiro, 2012.

CNI; PROCEL; ELETROBRÁS. Novas Tecnologias para processos industriais: Eficiência Energética na Indústria, 2009. Disponível em: < http://www. cni.org.br/portal/lumis/portal/file/fileDownload.sp?fileld=FF8080812C8533A0012C988AC19D61F0>. Acesso em 15 Ago 2013.

COSTA FILHO, C. F. F.; ALBUQUERQUE, A. T. de; COSTA, M. G. F. Luminance Optimization in Closed Environments by Simulated Annealing. In: IEEE Latin America Transactions, v. 8, n. 3, Jun., 2010.

REGIS FILHO, G. I. Ergonomia aplicada à odontologia: as doenças de caráter ocupacional e o cirurgião-dentista: produtividade com qualidade de vida no trabalho. Curitiba: Editora Maio, 2004.

GUIA TRABALHISTA. NR 15 atividades e operações insalubres: limites de tolerância para exposição ao calor. Disponível em:<http:// www.guiatrabalhista.com.br/legislacao/nr/ nr15_anexolll.htm>. Acesso em: 24 mai. 2014.

IIDA, I. Ergonomia: Projeto e produção. 2. ed. São Paulo: Edgar Blucher, 2005.

KROEMER, K. H. E.; GRANDJEAN, E. Manual de Ergonomia: Adaptado o trabalho ao homem. 5. ed. Porto Alegre: Bookman, 2005.

KUHN, P. D.; OLIVEIRA, C. C.; TAKEDA, F. Verificação da iluminância no ambiente de trabalho. In Encontro Nacional de Engenharia de Produção, 30, São Carlos. Anais... São Paulo: ENEGEP 2010.

LAMBERTS, R.; PEREIRA, F.; DUTRA, L. Eficiência Energética na Arquitetura. PW Gráficos e Editores Associados Ltda: São Paulo, 1997.

LOPES, R. F. Condições de conforto térmico na construção de edifícios. Dissertação de Mestrado. Engenharia de Segurança e Higiene Ocupacionais. Faculdade de Engenharia. Universidade do Porto, Faculdade de Ciências e Tecnologia. Universidade Fernando Pessoa. 2007.

MANAV, B. An experimental study on the appraisal of the visual environment at offices in relation to colour temperature and illuminance. Building and Environment. Elsevier, v. 42, n. 2, p. 979-983, fev., 2007. 
KOVALECHEN, M. T. B. A iluminação enquanto fator de alteração do desempenho no trabalho em ambientes corporativos. Especialize Revista On Line. Instituto de Pós-Graduação (IPOG), n. 4, p. 01-07, maio, 2012.

OKAMOTO, J. Percepção ambiental e comportamento: visão holística da percepção ambiental na arquitetura e na comunicação. São Paulo: Editora Mackenzie, 2002.

OROSA, J. A.; OLIVEIRA, C. O. A new thermal comfort approach comparing adaptive and PMV models. Renewable Energy, v.36, n. 3, p. 951-956, 2011.

PAIS, A. M. G. Condições de iluminação em ambiente de escritório: Influência no conforto visual. Dissertação (Mestrado em Ergonomia na Segurança do Trabalho) - Faculdade de Motricidade Humana, Universidade Técnica de Lisboa. Portugal, 2011.

RUAS, A. C. Conforto Térmico nos Ambientes de Trabalho. Ministério do trabalho FUNDACENTRO, São Paulo, 1999.

SANTOS, A. R. M.; LETA, F. R.; VELLOSO, M. $P$. Fatores de risco industrial causados por diferentes percepções de cores devido à diferença de iluminantes. Revista Produção Online. v. 5, n. 1, 2005.

OLIVEIRA, T. N; ASSIS, C. G; KRUGER, L. T. B. V; CARVALHO, M. C. R. Estudo do projeto de iluminação natural e artificial do Centro Administrativo do Governo de Minas Gerais: estudo de caso. Revista Educação e Tecnologia, v. 14, n.2, p. 14-21, 2009.

VALENTIM, A; FERREIRA, $\mathrm{H}$; COLETTO, M. Lâmpadas de LED: Impacto no consumo e no fator de potência. Revista Ciências do ambiente on-line, v. 6, n 1, 2010.

VAN BOMMEL, W. Incandescent replacement lamps and health. Van Bommel Lighting Consultant, p. 8, fev. 2011. 